\title{
The effect of Trichoderma on the growth and development of tomato and bean under greenhouse and field conditions
}

\author{
Gwendolyn Ban ${ }^{1 *}$, Shamsul Akanda' and Macquin Maino'
}

\begin{abstract}
Trichoderma's plant growth stimulating effect is well-recognized besides its well-known role as a biocontrol agent against plant diseases. Two greenhouse and field studies were conducted at the Papua New Guinea University of Technology (PNGUOT) to test the effects of Trichoderma harzianum on the growth of tomato and bean plants. Greenhouse potted plants were inoculated with three $T$. harzianum strains at $10^{6} \mathrm{CFUmL}^{-1}$, whereas, the field experiments were inoculated with T. harzianum strain LIPIMCO548 in rice bran at $0,25,50$ and $75 \mathrm{~g} / \mathrm{m}^{2}$ soil. In the greenhouse experiments, Trichoderma inoculation increased the root and shoot length, and total fresh weight of bean plant up to $16.57,20.79$ and $21.37 \%$, respectively over the un-inoculated control. For tomato plants, significantly higher ( $p \leq 0.05$, LSD) average root growth was observed when inoculated with $T$. harzianum strain CE262 over the control. On average, Trichoderma inoculation increased the root and shoot length, and the fresh weight up to $26.4,9.6$ and $18.8 \%$, respectively over the control. Similar growth patterns were also observed in the field experiments. These results will be of immense value to vegetable growers in Papua New Guinea (PNG), especially to the intensive vegetable growing areas in the highland regions of the country.
\end{abstract}

Keywords: Trichoderma hazianum, Lycopersicon esculentum, Phaseolus vulgaris, vegetable.

\section{INTRODUCTION}

Biological control is a promising strategy in controlling many destructive soilborne and foliar diseases that is compatible with sustainable agricultural system with no harmful effect on environment (Vinale et al 2009). Trichoderma spp. is one of the most common biocontrol agents against many plant pathogenic fungi causing soil-borne, air-borne and post-harvest diseases in a variety of crops (Harman et al 1989, Lo et al 1996).

\footnotetext{
'Department of Agriculture, Papua New Guinea University of Technology, Private Mail Bag, Lae 411. Morobe Province, Papua New Guinea

* Corresponding Author. Address: Department of Agriculture, Papua New Guinea University of Technology, Private Mail Bag, Lae 411, Morobe Province, Papua New Guinea; e-mail: gwendolyn.ban@pnguot.ac.pg DOI: $10.32945 /$ atr 4013.2018
} 
Trichoderma spp. are free living antagonistic fungi and are common inhabitants of all soil types and root ecosystems with biocontrol capabilities through mycoparasitism, antibiosis, competition, plant growth promotion and induced resistance (Hjeljord \& Tronsmo 1998). Some Trichoderma strains colonize plant root surfaces and penetrate into the epidermis and below (Baker 1988, Windham et al 1986). Trichoderma produces and releases a variety of compounds inciting localized or systemic resistance responses that explains their lack of pathogenicity to plants. Despite biocontrol, the root colonization by Trichoderma spp. usually improves plant growth and development, crop productivity, resistance to abiotic stresses and the uptake of nutrients by plants (Altomare et al 1999). The promotion of plant growth is an indirect Trichoderma activity that contributes to biocontrol of numerous plant pathogens, thus improving the health of the plants. Plants inoculated with Trichoderma had increased root and shoot growth, reduced activities of harmful organisms in the soil rhizosphere of plants, and improved nutrient uptake (Yedida et al 1999). Plant growth enhancement is also noticeable in the absence of detectable diseases in sterilized soil. Therefore, it is assumed that Trichoderma secretes hormone-like metabolites (Windham et al 1986), solubilizes insoluble trace nutrients (Altomare et al 1999), and increases translocation of scarce minerals (Baker 1989, Inbar et al 1994, Kleifeld \& Chet 1992); thus constitute some of the probable mechanisms leading to plant growth improvement.

The significant improvement in shoot length and weight, root length and weight, dry weight, and leaf area has been reported for crops like bean (Phaseolus vulgaris L.), cucumber (Cucumissativus L.), pepper (Capsicum annum L.) and wheat (Triticumaestivum L.) when treated with Trichoderma (Baker 1991, Chang et al 1986).

Isolates of Trichoderma harzianum produce 6-pentyl-a-pyrone (Zimand et al 1996) and harzianopyridone (Cutler \& Jayno 1991) with phytotoxic activities. Plant sensitivity to these compounds varies with the plant species (Cutler \& Jayno 1991, Zimandet et al 1996). Increased germinations were observed when wheat (Kucuk \& Kivanc 2003) and cabbage seeds (Rabeendran et al 2000) were treated with Trichoderma harzianum.

The hormonal activities of the Trichoderma spp. could be effectively used for the growth of many crops, particularly vegetables. Besides the enormous importance, no systematic research is being conducted in PNG to investigate and make use of the plant growth-promoting potential of Trichoderma spp. Separate greenhouse and field experiments were conducted to investigate the plant growthpromoting potential of Trichoderma on the growth and development of bean and tomato plants.

\section{MATERIALS AND METHODS}

\section{Greenhouse Experiment}

Two separate experiments with tomato (Lycopersicon esculentum) and bean (Phaseolus vulgaris) were conducted in 2013 and 2014 in the greenhouse of the Department of Agriculture of Papua New Guinea University of Technology (PNGUOT). Soil collected from the PNGUOT Agriculture farm was steam sterilized 
The effect of Trichoderma on the growth and development of tomato and bean

in a drum for $24 \mathrm{~h}$ and then allowed to cool before filling the polystyrene pots. Pots of $200 \mathrm{~mm}$ size used in the greenhouse experiment were also sterilized using $70 \%$ ethanol. Each of the pots was filled with $2 \mathrm{~kg}$ of sterilized soil and was inoculated separately with $100 \mathrm{~mL}^{(a b o u t} 10^{6} \mathrm{CFUmL}^{-1}$ ) of Trichoderma spore suspensions of three T. harzianum strains (CE 262, IB 596 and LIPIMC0548) isolated and identified in 2013 (Ban unpublished). The inoculated pots were covered with polyethylene sheet for a week before sowing of bean (var. Dwarf Bean) and tomato (var. Money Maker) at five seeds per pot. Potted plants for each strain along with corresponding un-inoculated control were replicated three times. The pots were arranged in a completely randomized design and each of the experiment was repeated twice.

Bean and tomato plants were harvested 33 and 61 days after planting (DAP), respectively. At harvest, plant roots were thoroughly washed and then growth parameters, such as root length, shoot length, and total fresh weight were recorded. The percentage growth improvement of the measured growth parameters of inoculated plants over un-inoculated control was determined using the formula (Rahman et al 2009):

$$
\text { Percentage plant growth }=\frac{\text { Trichoderma } \text { inoculated plants }- \text { Control }(\text { no Trichoderma })}{\operatorname{Control}(\text { no Trichoderma })} \times 100
$$

\section{Field Experiment}

Two separate field experiments were also conducted at the PNGUOT Agriculture farm with the same tomato and bean varieties as used in the greenhouse experiments. Land was ploughed and harrowed properly to prepare the seedbed. Twelve plots of $1.5 \mathrm{~m} \times 1.5 \mathrm{~m}$ were prepared for each crop to accommodate four treatments replicated thrice in a completely randomised block design. Plots were fumigated with methyl bromide at $24 \mathrm{~g} / \mathrm{m}^{2}$ and left for two weeks for chemical activity before planting.

For field inoculation, $500 \mathrm{~g}$ of rice bran in the conical flask was inoculated with $100 \mathrm{ml}$ spore suspension of T. harzianum strain LIPIMC0548 (about $10^{6} \mathrm{CFUmL}^{-1}$ ). Trichoderma inoculum in rice bran was applied at $25 \mathrm{~g}, 50 \mathrm{~g}$ and $75 \mathrm{~g} \mathrm{plot}^{-1}$ along with un-inoculated control. Inoculated plots were covered with black polythene plastic sheets for one week to allow T. harzianum to establish before seeding. Five seeds each of bean and tomato were sown at $60 \mathrm{~cm} \times 50 \mathrm{~cm}$ between plants, respectively. The trial was repeated twice.

Bean and tomato plants were harvested 56 and 70 DAP, respectively. Growth parameters, such as root length, shoot length, fresh weight, and root weight were recorded at the harvest. Percentage growth improvement of the measured parameters from the inoculated plants over un-inoculated control was determined applying the formula used in the greenhouse experiments.

\section{Statistical Analysis}

Preliminary analysis of variance (ANOVA) for the greenhouse and field experiments showed non-significant interactions between the treatments and 
season (trials); thus, a combined analysis was conducted over the trials. Data on different growth parameters were analysed using the statistical package STATISTIX version eight. Least significance difference (LSD) was used to determine the significant differences among the treatment means.

\section{RESULTS}

\section{Greenhouse Experiment}

The effects of three $T$. harzianum strains on the growth parameters of bean and tomato plants are presented in Table 1 and Table 2, respectively. There were no significant differences in root length, shoot length, and total fresh weight in the bean plants treated with the three strains of $T$. harzianum (Table 1). However, inoculation with $T$. harzianum had notably increased the root growth by 10.25 to $16.57 \%$; shoot length by 6.72 to $20.79 \%$; and the fresh weight by 10.26 to $21.37 \%$ over the control.

Tomato plants inoculated with $T$. harzianum, strain CE 262 had significantly $(p \leq 0.05)$ longer roots than the un-inoculated control (Table 2). No significant differences were observed among the three strains for any of the measured parameters. However, inoculation with Trichoderma strains showed increased root length by 3.2 to $26.4 \%$, shoot length by 2 to $9.6 \%$, and fresh weight by 8.3 to $18.8 \%$ over the un-inoculated control.

Table 1. Effect of Trichoderma inoculation on root length, shoot length, and total fresh weight of bean plants grown in the greenhouse at harvest at 33 DAP

\begin{tabular}{|c|c|c|c|c|c|c|}
\hline Trichoderma & $\begin{array}{l}\text { Root length } \\
\text { (cm) }\end{array}$ & $\begin{array}{l}\text { Root length } \\
\text { improvement } \\
\text { over control (\%) }\end{array}$ & $\begin{array}{c}\text { Shoot length } \\
(\mathrm{cm})\end{array}$ & $\begin{array}{l}\text { Shoot length } \\
\text { improvement } \\
\text { over control (\%) }\end{array}$ & $\begin{array}{l}\text { Total fresh } \\
\text { weight (g) }\end{array}$ & $\begin{array}{c}\text { Total fresh } \\
\text { weight } \\
\text { increase over } \\
\text { control (\%) }\end{array}$ \\
\hline $\begin{array}{l}\text { T. harzianum } \\
\text { strain CE262 }\end{array}$ & $17.52 a$ & 16.57 & $40.61 a$ & 20.79 & $28.4 a$ & 21.37 \\
\hline $\begin{array}{l}\text { T. harzianum } \\
\text { strain IB596 }\end{array}$ & $16.57 a$ & 10.25 & $39.73 a$ & 18.17 & $26.9 a$ & 14.98 \\
\hline $\begin{array}{l}\text { T. harzianum } \\
\text { strain } \\
\text { LIPIMC0548 }\end{array}$ & $16.79 a$ & 11.71 & $35.88 \mathrm{a}$ & 6.72 & $25.8 \mathrm{a}$ & 10.26 \\
\hline $\begin{array}{l}\text { Control (no } \\
\text { Trichoderma) }\end{array}$ & $15.03 \mathrm{a}$ & - & $33.62 a$ & - & $23.4 \mathrm{a}$ & - \\
\hline
\end{tabular}

Means followed by the same letter in a column are not significantly different at $p \leq 0.05$ (LSD) 
The effect of Trichoderma on the growth and development of tomato and bean

Table 2. Effect of Trichoderma inoculation on root length, shoot length, and total fresh weight of tomato plants grown in the greenhouse at harvest at 61 DAP

\begin{tabular}{|c|c|c|c|c|c|c|}
\hline Trichoderma & $\begin{array}{l}\text { Root length } \\
(\mathrm{cm})\end{array}$ & $\begin{array}{l}\text { Root length } \\
\text { improvement } \\
\text { over control } \\
(\%)\end{array}$ & $\begin{array}{c}\text { Shoot } \\
\text { length }(\mathrm{cm})\end{array}$ & $\begin{array}{c}\text { Shoot length } \\
\text { improvement } \\
\text { over control } \\
(\%)\end{array}$ & $\begin{array}{l}\text { Total fresh } \\
\text { weight. }(\mathrm{g})\end{array}$ & $\begin{array}{c}\text { Total fresh } \\
\text { weight } \\
\text { increase } \\
\text { over control } \\
(\%)\end{array}$ \\
\hline $\begin{array}{l}\text { T. harzianum } \\
\text { strain CE262 }\end{array}$ & $15.8 \mathrm{a}$ & 26.4 & $54.4 a$ & 2 & $57 a$ & 18.8 \\
\hline $\begin{array}{l}\text { T. harzianum } \\
\text { strain IB596 }\end{array}$ & $14.9 \mathrm{ab}$ & 19.2 & $58.4 a$ & 9.6 & $52 a$ & 8.3 \\
\hline $\begin{array}{l}\text { T. harzianum } \\
\text { strain } \\
\text { LIPIMC0548 }\end{array}$ & $12.9 \mathrm{ab}$ & 3.2 & $55.7 a$ & 4.5 & $57 a$ & 18.8 \\
\hline $\begin{array}{l}\text { Control (no } \\
\text { Trichoderma) }\end{array}$ & $12.5 b$ & - & $53.3 \mathrm{a}$ & - & $48 a$ & - \\
\hline
\end{tabular}

Means followed by the same letter in a column are not significantly different at $\mathrm{p} \leq 0.05$ (LSD).

\section{Field Experiment}

The effect of $T$. harzianum strain LIPIMCO548 on the growth parameters of bean plants grown in the field is presented in Table 3 . Roots of inoculated plants were significantly $(p \leq 0.05)$ longer with higher weight than the un-inoculated control. No significant differences were observed for any of the growth parameters at any levels of inoculum, even though, Trichoderma inoculation improved root length, shoot length, root weight, and total fresh weight by 18.5 to $26.9 \%, 0.4$ to $1.5 \%, 27.2$ to $42.2 \%$, and 10 to $25.9 \%$, respectively.

The effects of Trichoderma on the growth of tomato are shown in Table 4. No significant differences were observed in root length and root weight, but significantly $(p \leq 0.05)$ higher shoot length and total fresh weight were observed when plots were inoculated at $50 \mathrm{~g} \mathrm{plot}^{-1}$ compared to un-inoculated control. Overall, Trichoderma inoculation improved the root length, shoot length, root weight, and total fresh weight by 19.9 to $35 \%, 0$ to $20.3 \%, 21.4$ to $35.8 \%$, and 12.9 to $60.8 \%$, respectively. 
Ban, Akanda \& Maino

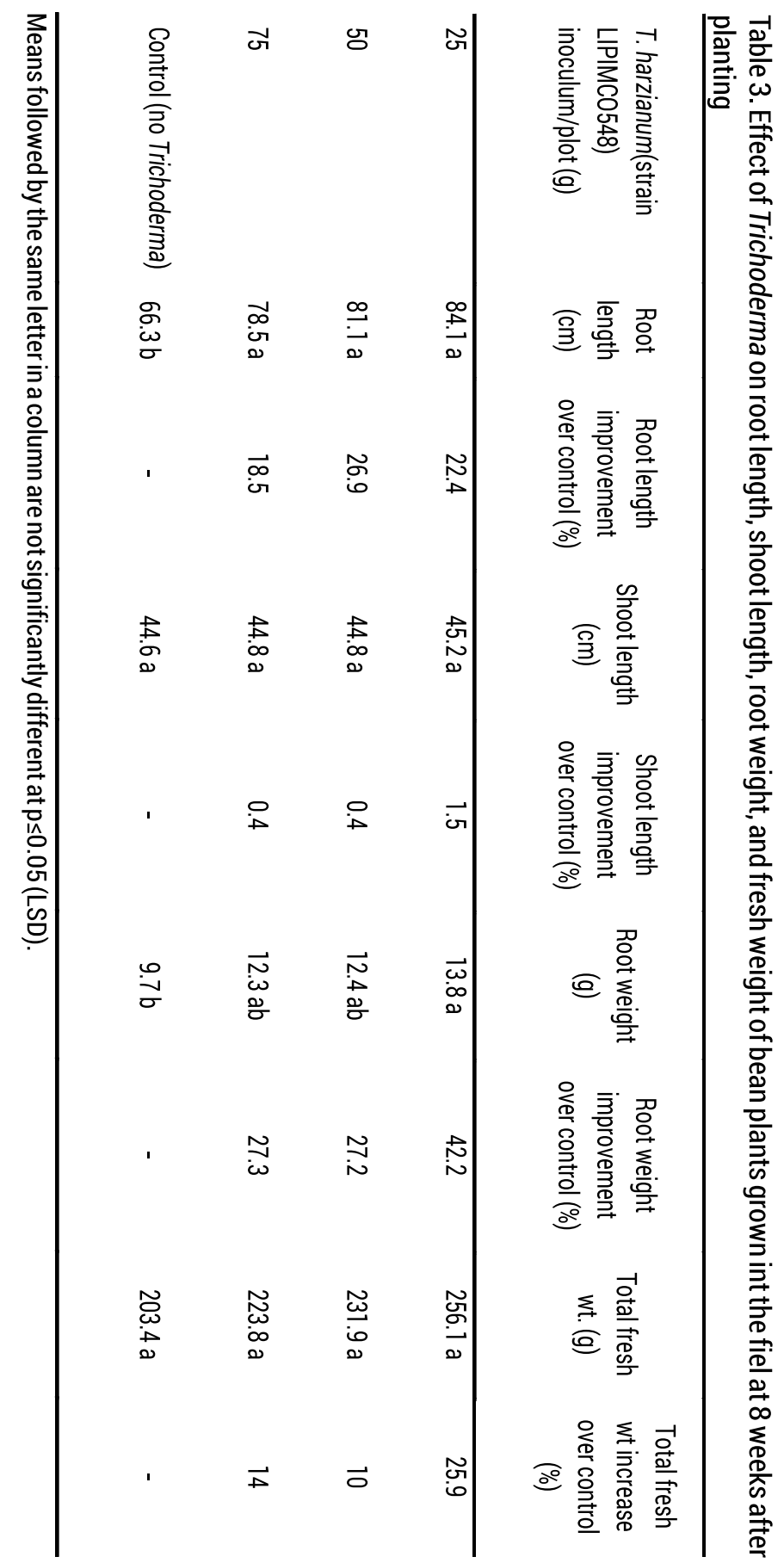


The effect of Trichoderma on the growth and development of tomato and bean

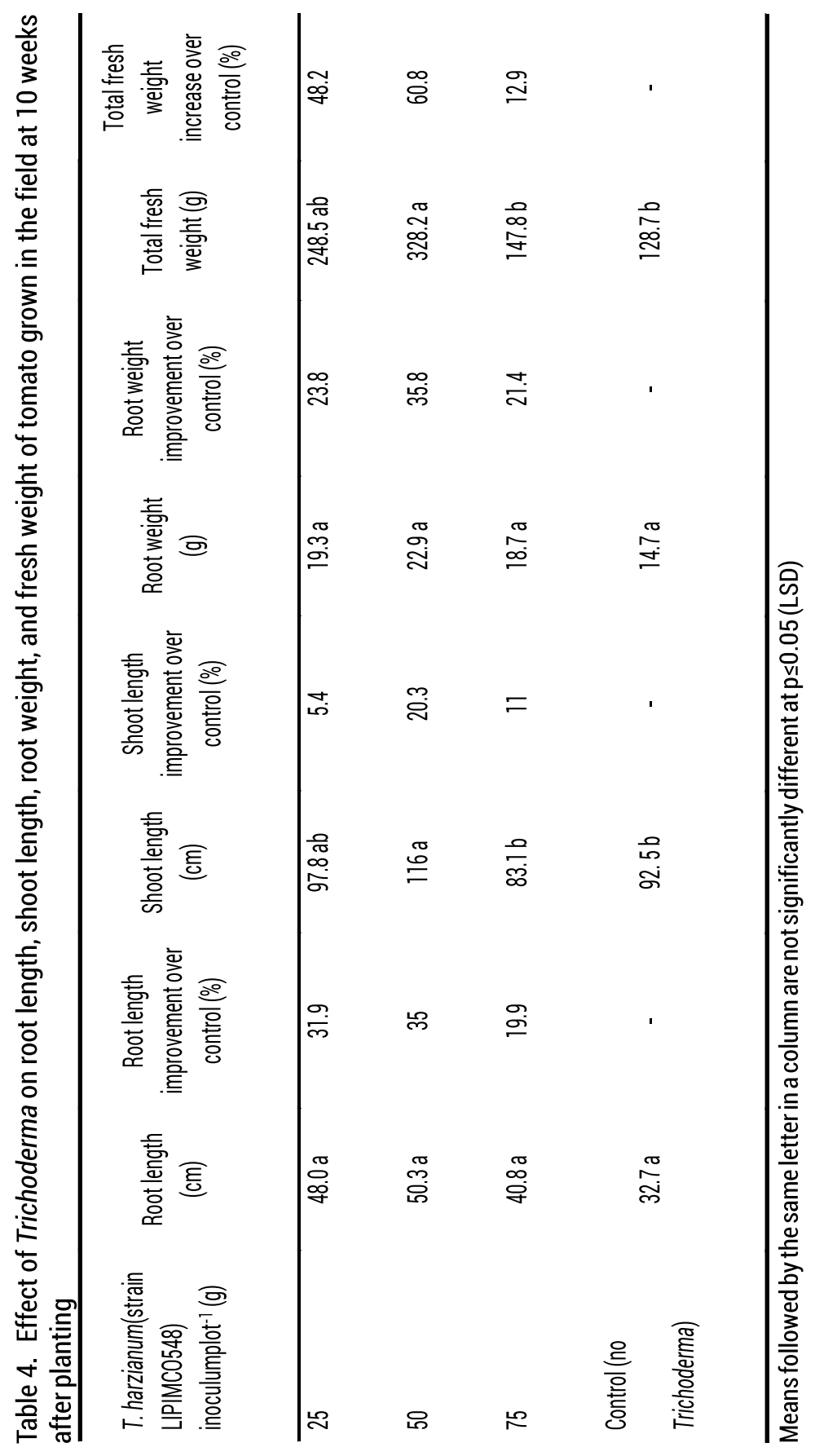


Ban, Akanda \& Maino

\section{DISCUSSION}

Inoculation of plants with Trichoderma induces plant growth and development (Ban et al 2013) even though, the principles of these growth responses are not fully understood (Altomare et al 1999, Celar \& Valic 2005). The positive effect of Trichoderma on plant growth is speculated to be an independent ability that is as important as its antifungal ability as the growth improvement has been observed both in the absence of any disease and in sterile soils (Altomare et al 1999, Ban 2015, Celar \& Valic 2005). This is consistent with the greenhouse and field results on overall growth improvement in inoculated bean and tomato plants over un-inoculated control in the current study.

Several factors, like direct production of growth stimulating factors (ie, plant hormones or growth regulators), increased fertilizer use efficiency, stimulation of plant defences against biotic and abiotic stresses, increased nutrients uptake through improved root growth or enhanced availability of necessary nutrients and decrease in concentrations of plant growth inhibitory substances in the soil may be responsible for increased plant growth (Kleifield \& Chet 1992, Suresh et al 2010 , Windham et al 1986). Increased root growth and associated plant growth improvement are reported to be caused both by biocontrol and related effects on root associated microflora, and by a direct improvement in plant growth (Harman et al 2004). However, in these experiments, the enhanced growth due to Trichoderma may not be attributed to its biological control ability as sterilized soil was used. Trichoderma was reported to enhance the nutrient uptake ability of plants indicating an improvement in plant active-uptake mechanisms and help in overcoming stresses of abiotic factors (Harman et al 2004) that might have been the case in these experiments. Rhizosphere colonization of Trichoderma are also reported to have induced higher photosynthetic activity and $\mathrm{CO} 2$ absorption in leaves leading to increased plant growth (Vargas et al 2009). In addition, root colonization by strains of Trichoderma also results in the increased levels of defence-related plant enzymes, which includes various peroxidases, chitinases, $\beta$-1, 3-glucanases, and the lipoxygenase-pathway hydroperoxidelyase (Harman et al 2004). When applied with plant material, such as rice bran, it increases the root lengths, thus, increases the ability of the plants to resist drought. In the current field experiments, this phenomenon was observed in bean plants when a Trichoderma strain LIPIMCO548 was applied with rice bran.

Strains of Trichoderma also solubilize phosphates and micronutrients leading to its increased availability (Ranasingh et al 2006). Similar studies by Kucuk and Kivanc (2003) on wheat showed that T. harzianum improved wheat plant height, root dry weight, and shoot dry weight. Increased solubilization of phosphate by Trichoderma harzianum increased nodulation of some legume crops (Podile 1995). The increased growth response due to inoculation with $T$. harzianum depends on its ability to survive and develop in the rhizosphere. A likely mechanism for the increased plant growth may be due to higher amount of nutrient transfer from the soil to the root. This is supported by the fact that Trichoderma can colonize the interior of roots (Kleifeld \& Chet 1992). Contreras-Cornejo et al (2009) also reported the production of auxin with stimulating effect of plant growth and root development. The positive effects of Trichoderma against abiotic stresses through induced physiological protection in plants against oxidative damages (Mastouri et al 2010) could also be responsible for improved root and plant growth 
The effect of Trichoderma on the growth and development of tomato and bean

and development as was observed in case of tomato and bean plants in the current trials.

Tomato plants in the current study under field condition did not perform well when Trichoderma was inoculated at $75 \mathrm{~g}$ of rice bran plot ${ }^{-1}$. This may be due to the higher concentration of Trichoderma, which adversely affected the growth of plants, such as stunting (Windham et al 1986). The slight inhibitory effect of Trichoderma may also be due to the production of volatile pentyl- and pentenylpyrones by $T$. harzianum (Lumsden et al 1990) other than its fungistatic and biocontrol effect, leading to phytotoxic side effects.

The native isolates of Trichoderma strains used in the current study did have overall positive effects on the growth parameters of bean and tomato. The results of this investigation could be of significant value to the vegetable growers in Papua New Guinea, particularly in the highlands regions.

\section{ACKNOWLEDGMENT}

The authors acknowledge the Department of Agriculture of the PNG University of Technology for the financial support towards completion of this research.

\section{REFERENCES}

Altomare C, Norvell WA, Bjorkman T \& Harman GE. 1999. Solubilization of phosphates and micronutrients by the plant-growth promoting and biocontrol fungus Trichoderma harzianum Rifai 1295-22. Applied Environmental Microbiology, 65:2926-2933.

Baker R. 1988. Trichoderma spp. as plant-growth stimulants. CRC Critical Reviews in Biotechnology, 7:97-105.

Baker R. 1991. Induction of rhizosphere competence in the biocontrol fungus Trichoderma. In Keisterand LD \& Cregan PB (eds), The Rhizosphere and Plant Growth (pp221-228). Kluwer Academic Publishers, Boston.

Ban G, Akanda S \& Maino M. 2013. Study on the effectiveness of Trichoderma spp. on the growth of bean and tomato plants under greenhouse condition. In Proceedings of the $7^{\text {th }}$ Huon Seminar, 13-14 Nov 2013, The PNG University of Technology, Lae, Papua New Guinea.

Ban G. 2015. The effectiveness of trichoderma species as a biocontrol agent against selected soilborne fungi (PhD dissertation), Papua New Guinea University of Technology, Morobe, PNG.

Celar F and Valic N.2005. Effects of Trichoderma spp. and Glicladiumroseum culture filtrates on seed germinations of vegetables and maize. JPlant Disease Protection, 112(4):343-350.

Chang YC, Chang YC, Baker R, Kleifeld O \& Chet I. 1986. Increased growth of plants in presence of the biological control agent, Trichoderma harzianum. Plant Diseases, 70:145-148.

Contreras-Cornejo HA, Mac'IAS-Rodr' iguez L, Corte'S-penagos C \& Lo' Pez-Bucio J. 2009. Trichoderma virens, a plant beneficial fungus, enhances biomass production and promotes lateral root growth through an auxin-dependent mechanism in Arabidopsis. Plant Physiology, 149:1579-1592. 
Cutler HG and Jayno JM. 1991. Biological activity of harzianopyridone isolated from Trichoderma harzianum. Agricultural \& Biological Chemistry, 55:26292631.

Harman GE, Taylor AG \& Stasz TE. 1989. Combining effective strains of Trichoderma harzianum and solid matrix priming to improve biological seed treatments. Plant Diseases, 73:631-637.

Harman GE, Howell CR, Viterbo A, Chet I \& Lorito M. 2004. Trichoderma species: Opportunistic, avirulent plant symbionts. Nature Reviews Microbiology, 2:4356.

Hjeljord L and Tronsmo A. 1998. Trichoderma and Gliocladium in biological control: an overview. In Kubicek CP \& Harman GE (eds), Trichoderma and Gliocladium (pp131-152). Taylor \& Francis, London.

Kleifeld $O$ and Chet I. 1992. Trichoderma harzianum interaction with plants and effect on growth response. Plant \& Soil, 144:267-272.

Kucuk $C$ and Kivanc M. 2003. Isolation of Trichoderma spp. and determination of their antifungal and biochemical, physiological features. Turkish J Biology, 27:247-253.

Lo CT, Nelson EB \& Harman GE. 1996. Biological control of turf grass diseases with rhizosphere competent strain of Trichoderma harzianum. Plant Diseases, 80:736-741.

Lumsden RD, Carter JP, Whipps JM \& Lynch JM. 1990. Comparison of biomass and viable propagule measurements in the antagonism of Trichoderma harzianum against Pythiumultimum. Soil Biology \& Biochemistry, 22:187-194.

Mastouri F, Bjo"rkman T \& Harmange GE. 2010. Seed treatment with Trichoderma harzianum alleviates biotic, abiotic, and physiological stresses in germinating seeds and seedlings. Phytopathology, 100:1213-1221.

Podile AR. 1995. Seed bacterization with Bacillus subtilis Af1 enhances nodulation in pigeon pea. Indian J Microbiology, 42:533-538.

Rabeendran N, Miot DJ, Jones EE \& Stewart A. 2000. Inconsistent growth promotion of cabbage and lettuce from Trichoderma isolates. New Zealand Plant Protection, 53:143-146.

Rahman MA, Begum MF \& Alam MF. 2009. Screening of Trichoderma Isolates as a Biological Control Agent against Ceratocystisparadoxa Causing Pineapple Disease of Sugarcane. Mycobiology, 37(4):277-285. doi:10.4489/MYC0.2009.37.4.277

Ranasingh N, Saurabh A \& Nedunchezhiyan M. 2006. Use of Trichoderma in disease management. Orissa Review, Sep-Oct: 68-70.

Shoresh M, Harman GE \& Mastouri F. 2010. Induced systemic resistance and plant responses to fungal biocontrol agents. Annual Review of Phytopathology, 48:21-43.

Vargas WA, Mandawe JC \& Kenerley CM. 2009. Plant-derived sucrose is a key element in the symbiotic association between Trichoderma virens and maize plants. Plant Physiology, 151:792-808.

Vinale F, Ghisalberti EL, Sivasithamparam K, Marra R, Ritieni A \& Lorito M. 2009. Factors affecting the production of Trichoderma harzianum secondary metabolites during the interaction with different plant pathogens. Letters in Applied Microbiology, 48:705-711.

Yedidia I, Benhamou N \& Chet I. 1999. Induction of defense responses in cucumber plants (Cucumissativus L.) by the biocontrol agent Trichoderma harzianum. 
The effect of Trichoderma on the growth and development of tomato and bean

Windham MT, Elad Y \& Baker R. 1986. A mechanism for increased plant growth induced by Trichoderma spp. Phytopathology, 76:518-521.

Zimand G, Elad I \& Chet I. 1996. Effect of Trichoderma harzianum on Botrytis cinerea pathogenicity. Phytopathology, 86:1255-1260. 